\title{
Efficacy of intraperitoneal and intravenous chemotherapy and left upper abdominal evisceration for advanced gastric cancer
}

\author{
Eiji Nomura, Masami Niki, Keizou Fuji, Hisashi Shinohara, Kanji Nishiguchi, Toyooki Sonoda, \\ and NobUhiko TANigawa \\ Department of General and Gastroenterological Surgery, Osaka Medical College, 2-7 Daigaku-machi, Takatsuki 569-8686, Japan
}

\begin{abstract}
Background. The study was carried out to evaluate the efficacy of intraperitoneal (IP) and intravenous (IV) chemotherapy, as well as left upper abdominal evisceration (LUAE), for patients with advanced gastric cancer.

Methods. We carried out a retrospective study of 348 patients who underwent gastrectomy for advanced gastric carcinoma between 1978 and 1998 at our institution and who had macroscopic type 3 or 4 cancer (Japanese classification) with depth of invasion to the serosal surface, but no liver metastasis or lymph node metastasis around the abdominal aorta. Cumulative survival rates were compared in patients who underwent gastrectomy together with: (1) intraoperative IP chemotherapy alone, (2) postoperative IV chemotherapy alone, (3) both IP and IV, or (4) no chemotherapy. Then patients were stratified according to the presence of peritoneal dissemination $(\mathbf{P}+)$ and its absence $(\mathbf{P}-)$. In $\mathbf{P}+$ patients, survival was compared between those who received IV chemotherapy and those who did not, and between those who received IP chemotherapy and those who did not. Then, survival was compared between patients with high and low immunosuppressive acidic protein (IAP) levels. Finally, we compared cumulative survival rates in patients (stratified as $\mathbf{P}+$ and $\mathbf{P}-$ ) who underwent LUAE with cumulative survival rates in those who underwent total gastrectomy combined with resection of the pancreatic body, tail, and spleen (PS).

Results. For $\mathbf{P}-$ patients, there was no survival advantage with adjuvant IP or IV therapy when compared with surgery alone. For $\mathrm{P}+$ patients, however, there was an improvement in survival when patients received both IP and IV, compared with survival with surgery alone $(P<0.05)$. In $P+$ patients aged less than 60 years, there was improvement in survival for those who underwent IP therapy together with surgery $(P<$ 0.05), but not for those who had IV chemotherapy after surgery. When LUAE was examined, there was a survival advantage for this procedure when there was no peritoneal dissemination. Four long-term survivors (surviving for more than 5 years) were identified in our study. Three of the 4
\end{abstract}

Offprint requests to: E. Nomura

Received: January 18, 2001 / Accepted: June 13, 2001 patients were aged less than 60 years, and all 4 had macroscopic type 4 gastric cancers.

Conclusion. Although the prognosis for patients with invasive type gastric cancer remains poor, there have been a few longterm survivors, in whom this survival was associated with aggressive combination therapy, including surgery, IP, and IV therapy. $P+$ patients aged less than 60 years and patients with type 4 gastric cancer may stand to benefit most from such therapy. For $\mathbf{P}$ - patients, the role of adjuvant IP or IV therapy continues to be ambiguous, although LUAE in this population may be superior to PS.

Key words Invasive gastric cancer - Intraperitoneal and intravenous chemotherapy · Left upper abdominal evisceration.

\section{Introduction}

Although surgical techniques have improved, the prognosis for patients with invasive type gastric carcinoma remains poor. Those with serosal invasion, in particular, tend to have peritoneal dissemination and distant lymph node metastasis, and as a result, the prognosis in this group, even with curative resections, has remained unsatisfactory [1]. Kajitani et al. [2], in 1982, and in 1984, the same group (Oohashi et al. [3]), reported a new operation for advanced gastric cancer: the en-bloc resection of the left side upper abdominal organs, including the whole stomach, omentum, body and tail of the pancreas, spleen, and transverse colon. The aim of this operation (left upper abdominal evisceration; LUAE) was to remove not only the primary tumor but also the extensive lymphatic system around the stomach, as well as to remove foci of macroscopically invisible peritoneal dissemination on the omental bursa.

In patients with invasive, in particular, scirrhous gastric carcinoma, with curability A or B (those with no obvious residual tumor; Japanese classification [4]) we have employed LUAE. In contrast, we have tradition- 
ally performed simple gastrectomy for the patients who fall into the category of curability $\mathrm{C}$ (definite residual tumor), or those with subjective symptoms. On a caseby-case basis, we have also administered intraperitoneal (IP) anticancer drug therapy at the time of surgery, as well as employing intravenous (IV) administration postoperatively. For IP therapy, our routine is to use mitomycin C (MMC) alone. With higher doses of MMC, however, we have used a combination of MMC with activated carbon particles (MMC-CH) [5], because $\mathrm{MMC}-\mathrm{CH}$ given intraperitoneally seems to adhere rapidly to the omentum, as well as to the subphrenic/pelvic peritoneum, and to be absorbed into the lymphatic system. The carbon particles slowly release the anticancer agent, and this allows the MMC concentration in the peritoneal cavity to remain high, while the rate of adverse effects is lower than with MMC alone. It was our aim in this study to investigate the efficacy of these individual therapies.

\section{Patients and methods}

We retrospectively analyzed results for 348 patients who, in the period 1978 to 1998, underwent gastrectomy for advanced gastric carcinoma at our institution. All patients had macroscopic type 3 or 4 cancers (Japanese classification [4]), with depth of invasion to the serosal surface, and with no liver metastasis or lymph node metastasis around the abdominal aorta. There were 284 patients without peritoneal dissemination $(\mathrm{P}-)$ and 64 patients with peritoneal dissemination $(\mathrm{P}+)$. Seven patients with positive cytology $[\mathrm{P} 0, \mathrm{cy}(+)]$ were included in the $\mathrm{P}+$ group. Table 1 shows the details of the 348 patients according to their stratification as $\mathrm{P}+$ and $\mathrm{P}-$.

Cumulative survival rates were compared in patients who underwent gastrectomy followed by: (1) intraoperative IP chemotherapy alone, (2) postoperative IV chemotherapy alone, (3) both IP and IV, or (4) no chemotherapy. These patients were stratified according to the presence of peritoneal dissemination $(\mathrm{P}+)$ and its absence $(\mathrm{P}-)$. In $\mathrm{P}+$ patients, survival was compared between those who received IV chemotherapy and those who did not, and between those who received IP chemotherapy and those who did not. Patients with clinically detectable ascites were excluded from this analysis. For reference, to assess the relevance of a competent immune system, survival was compared between patients with high and low immunosuppressive acidic protein (IAP) levels [6], although the number of patients in whom we assessed the IAP levels was small. Finally, we compared cumulative survival rates in patients (stratified as $\mathrm{P}+$ and $\mathrm{P}-$ ) who underwent LUAE with cumulative survival rates in those who underwent total gastrectomy combined with resection of the pancreatic body, tail, and spleen (PS).

IP chemotherapy was first used in 1982 at our institution, but selection criteria meant that it was rarely used. Since the introduction of MMC-CH in 1987, IP chemotherapy has often been selected for $\mathrm{P}-$ patients, but IV chemotherapy tends not to be selected for patients with several risk factors. For P+ patients, whether IP or IV chemotherapy was administered depended on the decision of the individual chief physician. Some chief physicians used mainly orally administered anticancer chemotherapy. This study does not include oral chemotherapy that patients after leaving hospital. Before we employed LUAE, we had performed PS for patients received with indications similar to those now used for LUAE.

Clinicopathological findings were analyzed in accordance with the Japanese classification of gastric carcinoma of the Japanese Research Society for Gastric Cancer [4]. The Kaplan-Meier method was used to construct the survival curves, and the generalized Wilcoxon test was used to compare survival curves.

\section{Results}

The details of IP and IV therapies are shown in Table 2 and Table 3, respectively. More $\mathrm{P}-$ patients than $\mathrm{P}+$ patients received IP therapy; 56.3\% (160/284) of the $\mathrm{P}-$ patients received only IV therapy.

Table 1. Details of 348 patients with gastric carcinoma stratified as $\mathrm{P}(-)$ or $\mathrm{P}(+)$

\begin{tabular}{|c|c|c|c|c|c|c|c|c|c|}
\hline & \multicolumn{2}{|c|}{$\begin{array}{c}\text { Macroscopic } \\
\text { type }^{\mathrm{a}}\end{array}$} & \multicolumn{4}{|c|}{$\begin{array}{l}\text { Histological findings of lymph } \\
\text { node metastasis }\end{array}$} & \multicolumn{3}{|c|}{$\begin{array}{l}\text { Macroscopic depth of } \\
\text { tumor invasion }^{\text {a }}\end{array}$} \\
\hline & Type 3 & Type 4 & $\mathrm{n} 0$ & $\mathrm{n} 1$ & $\mathrm{n} 2$ & $\mathrm{n} 3$ & $\mathrm{~T} 2$ & $\mathrm{~T} 3$ & $\mathrm{~T} 4$ \\
\hline $\mathrm{P}(-) ; n=284$ & $174(61.3)$ & 110 (38.7) & $58(20.4)$ & $105(37.0)$ & $87(30.6)$ & $34(12.0)$ & $26(9.1)$ & $227(80.0)$ & 31 (10.9) \\
\hline $\mathrm{P}(+) ; n=64$ & $29(45.3)$ & $35(54.7)$ & $4(6.3)$ & 17 (26.6) & $30(46.9)$ & $13(20.3)$ & $0(0)$ & $48(75.0)$ & $16(25.0)$ \\
\hline
\end{tabular}

Figures in parentheses are percentages

$\mathrm{P}$, Peritoneal dissemination

a These findings were analyzed in accordance with the Japanese classification of gastric cancer [4] 
Figure 1A demonstrates the comparative survival of both $\mathrm{P}+$ and $\mathrm{P}-$ patients who underwent gastrectomy alone, gastrectomy plus IP (or IV), or gastrectomy plus both IP and IV. In the P- patients, no survival difference was found among the four groups. In contrast, in $\mathrm{P}+$ patients, the survival rate of those who received both IP and IV was significantly higher than that in those who received no adjuvant therapy $(P<0.05$; Fig. 1B). Details of these $\mathrm{P}+$ patients are shown in Table 4.

Figure 2A demonstrates the differences in survival among $\mathrm{P}+$ patients who did and did not receive IV therapy. There was no detectable survival advantage with IV therapy, even when patients less than 60 years old were studied independently (Fig. 2C). This was not the case when $\mathrm{P}+$ patients who underwent IP therapy were compared with those who did not (Fig. 2B). In the group of patients less than 60 years old, an improved survival rate was seen in the IP + group $(n=22)$ compared with the IP- group $(n=10)(P<0.05)$ (Fig. 2D). However, there was no survival advantage with MMC$\mathrm{CH}$ when compared with $\mathrm{MMC}$ alone in either $\mathrm{P}+$ or $\mathrm{P}-$ patients. In $\mathrm{P}+$ patients less than 60 years old, 5fluorouracil (FU) derivatives were given orally in $69.2 \%$ $(18 / 26)$ of the IV + group, $66.7 \%(4 / 6)$ of the IVgroup, $72.7 \%(16 / 22)$ of the IP+ group, and $60.0 \%$

Table 2. IP therapy (intraperitoneal administration of anticancer drugs during surgery)

\begin{tabular}{lrrr}
\hline & $n$ & $\mathrm{P}(-)$ & $\mathrm{P}(+)$ \\
\hline CH + MMC 30mg IP & 26 & 20 & 6 \\
CH + MMC 40mg IP & 4 & 3 & 1 \\
CH + MMC 50mg IP & 29 & 18 & 11 \\
MMC 10mg alone IP & 15 & 12 & 3 \\
MMC 20mg alone IP & 31 & 20 & 11 \\
MMC 30mg alone IP & 5 & 1 & 4 \\
Total & 110 & 74 & 36 \\
\hline
\end{tabular}

$\mathrm{CH}+\mathrm{MMC}$, Activated carbon particles $(\mathrm{CH})$ plus mitomycin $\mathrm{C}$ (MMC)
(6/10) of the IP - group after they left hospital; there were no significant differences among these groups. Of note, the number of gastric cancers located in the whole stomach was significantly higher in the IP + group than in the IP- group (Table 5).

Next, the survival rates of patients with high IAP levels (IAP, $\geqq 450 \mathrm{ng} / \mathrm{ml} ; n=15$ ), and low IAP levels (IAP, $<450 \mathrm{ng} / \mathrm{ml} ; n=10$ ) were compared. In patients who underwent gastrectomy plus IP, there was a survival advantage in those with lower IAP levels $(P<$ 0.05) (Fig. 3). Table 6 shows the details of these 25 patients.

Figure $4 \mathrm{~A}$ shows the survival rates among $\mathrm{P}-$ patients who underwent LUAE $(n=26)$ versus the Ppatients with PS $(n=41)$. The survival rate in the LUAE group was significantly higher than that in the PS group $(P<0.05)$. In $\mathrm{P}+$ patients, this survival difference between the LUAE group $(n=9)$ and the PS group $(n=8)$ was not found (Fig. 4B). Table 7 shows the details of the LUAE and PS groups in $\mathrm{P}-$ patients.

We were able to identify four patients with peritoneal dissemination who survived for more than 5 years (Table 8). All of these patients had macroscopic type 4 tumors. The first three patients were aged less than 60 years, while the fourth was aged 65 years. The three younger long-term survivors received both IP and IV therapy after gastrectomy. Two of the four patients underwent LUAE.

\section{Discussion}

Among various types of advanced gastric cancer, invasive gastric cancer with serosal invasion tends to have a poor prognosis, because of peritoneal dissemination and distant lymph node metastasis. The role of intraoperative IP therapy and postoperative IV therapy in these patients remains controversial. In this study, we focused specifically on patients with macroscopic type

Table 3. IV therapy (intravenous administration of anticancer drugs after surgery)

\begin{tabular}{lrrrrr}
\hline & \multicolumn{2}{c}{$\mathrm{P}(-)$} & & \multicolumn{2}{c}{$\mathrm{P}(+)$} \\
\cline { 2 - 3 } \cline { 5 - 6 } & $\mathrm{IP}(-)$ & $\mathrm{IP}(+)$ & & $\mathrm{IP}(-)$ & $\mathrm{IP}(+)$ \\
\hline FMC (MMC/FT207) & 122 & 38 & & 14 & 20 \\
MMC & 10 & 5 & & 2 & 1 \\
Sequential (MTX/5-FU) & 9 & 12 & & 2 & 3 \\
Low-dose CDDP+5-FU & 19 & 7 & & 4 & 3 \\
$\quad$ Number of patients undergoing & 160 & 62 & & 22 & 27 \\
$\quad$ chemotherapy after surgery & 50 & 12 & & 6 & 9 \\
$\quad$ gumber of patients not under- & & & & 36 \\
$\quad$ Total & 210 & 74 & & 28 & \\
\hline
\end{tabular}

FT207, Futraful; MTX, methotrexate; 5-FU, 5-fluorouracil; CDDP, cisplatin 


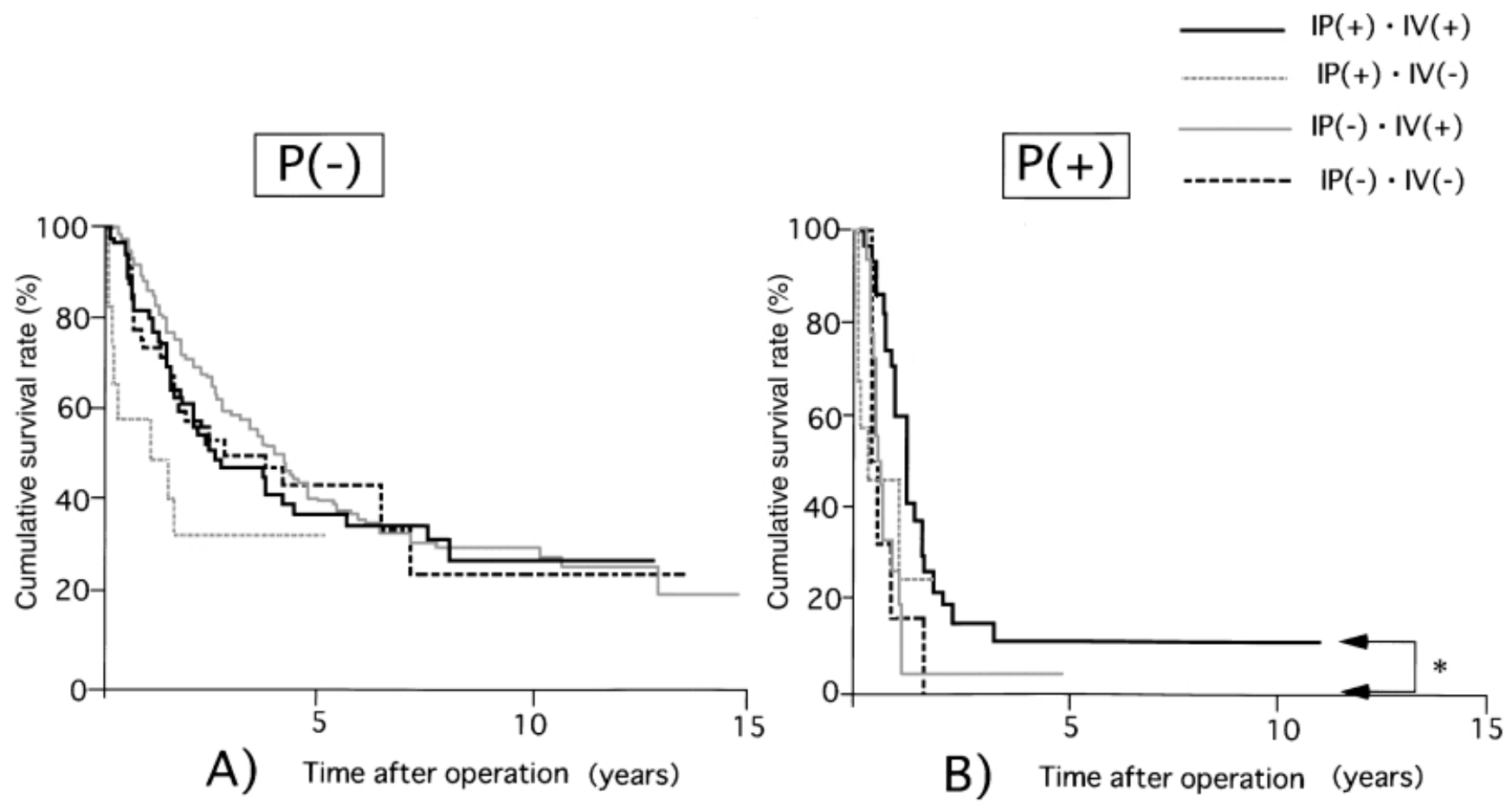

Fig. 1A,B. Survival of patients who underwent gastrectomy alone, gastrectomy plus $I P$ therapy (intraperitoneal administration of anticancer drugs during surgery), or gastrectomy plus $I V$ therapy (intravenous administration of anticancer drugs after surgery), or gastrectomy plus both IP and IV therapies. A Patients without intraperitoneal dissemination $(P-)$; $\mathbf{B}$ patients with intraperitoneal dissemination $(P+)$. $* P<0.05$

Table 4. Details of $\mathrm{P}+$ patients according to IP and IV chemotherapies

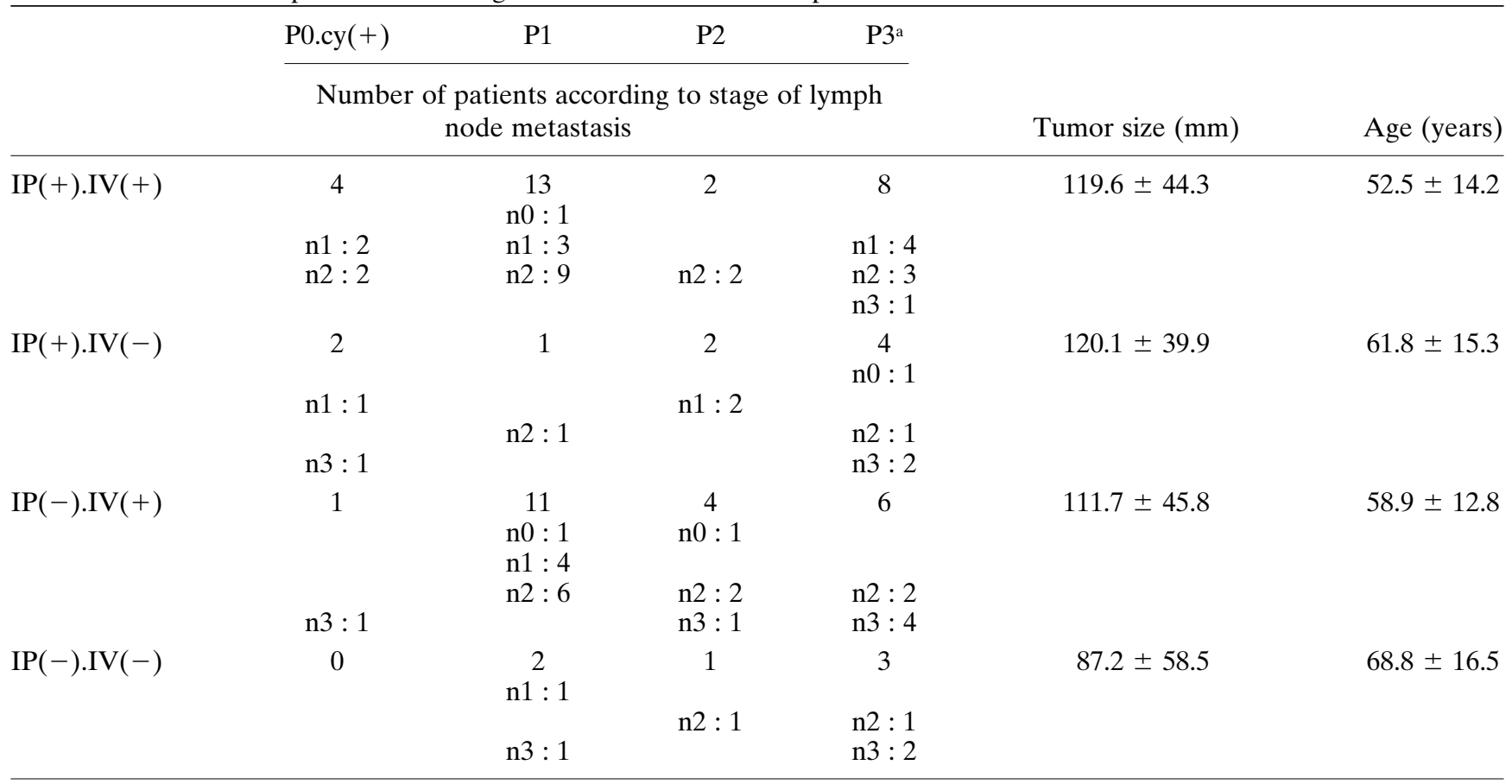

${ }^{a}$ Classified according to reference [4] 


\section{All patients}

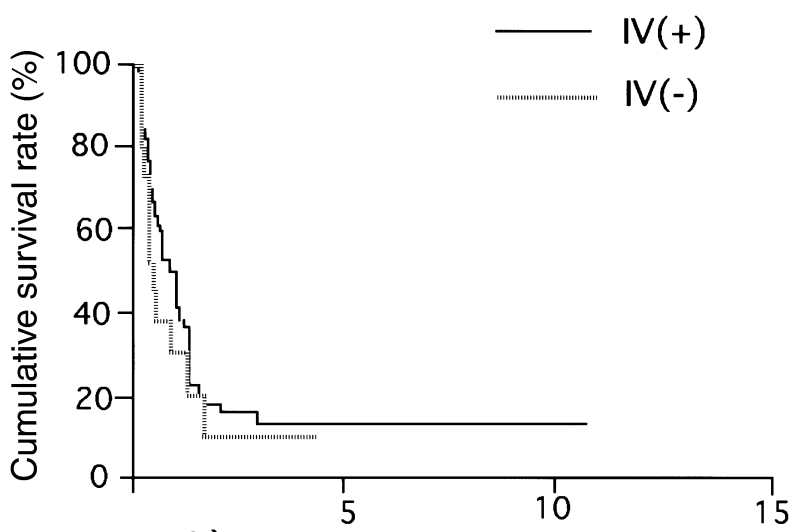

A) Time after operation (years)

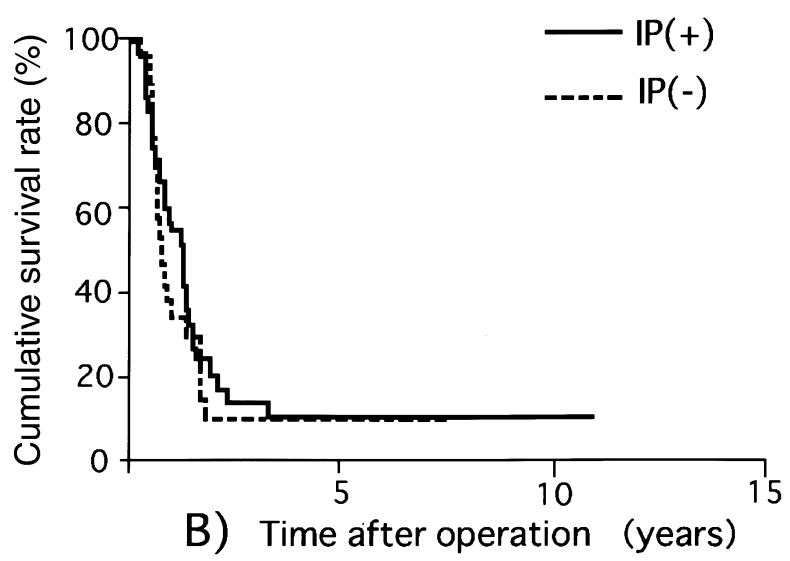

Patients less than 60 years old
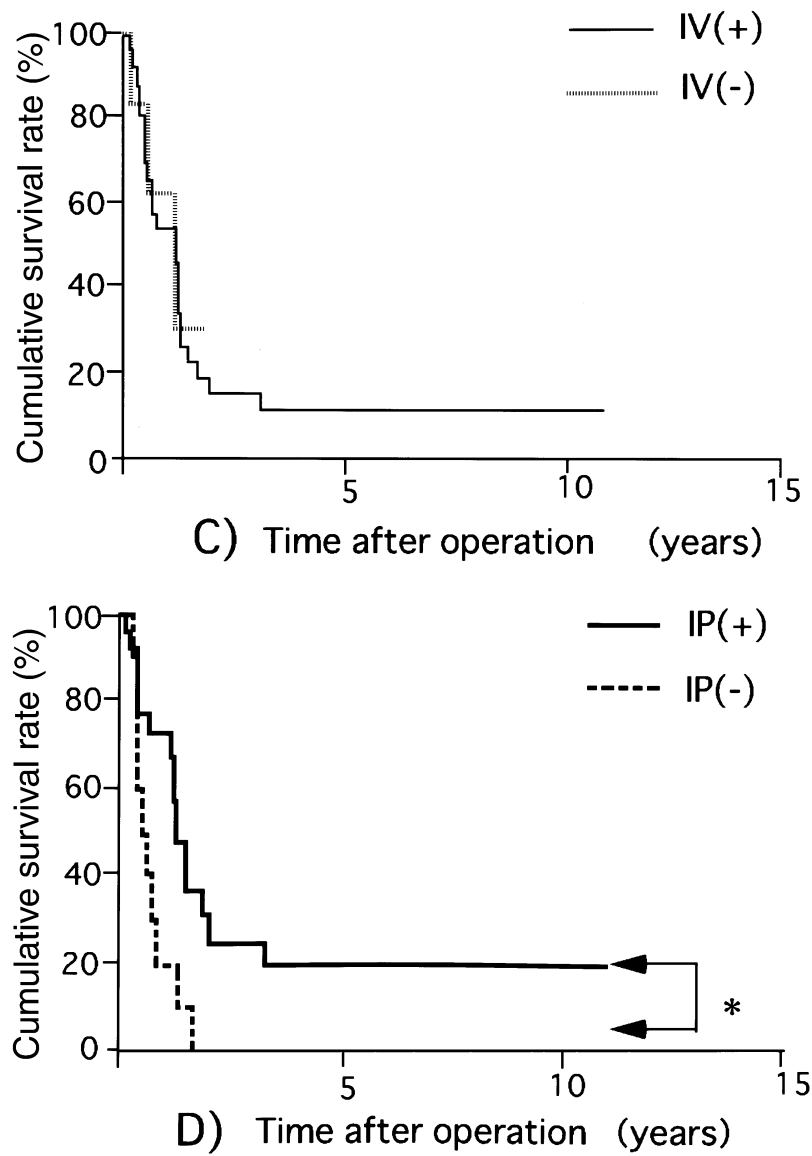

Fig. 2A-D. Survival of $\mathrm{P}+$ patients who received either IV therapy or IP therapy. A Survival of all $\mathrm{P}+$ patients who did and did not receive IV therapy. B Survival of all P+ patients who did and did not receive IP therapy. C Survival of P+ patients less than 60 years old who did and did not receive IV therapy. D Survival of P+ patients less than 60 years old who did and did not receive IP therapy. ${ }^{*} P<0.05$

Table 5. Use of 5-FU derivatives (given orally) and location of gastric cancer in the 32 $\mathrm{P}+$ patients who were aged less than 60 years

\begin{tabular}{|c|c|c|c|c|c|c|}
\hline & \multicolumn{2}{|c|}{$\begin{array}{c}\text { Use of 5-FU } \\
\text { derivatives }\end{array}$} & \multicolumn{4}{|c|}{ Location of gastric cancer } \\
\hline & Used & Not used & $\mathrm{U}$ & M & $\mathrm{L}$ & W \\
\hline $\begin{array}{l}\operatorname{IP}(+) \\
\operatorname{IP}(-)\end{array}$ & $\begin{array}{r}16(72.7) \\
6(60.0)\end{array}$ & $\begin{array}{l}6(27.3) \\
4(40.0)\end{array}$ & $\begin{array}{l}4(18.2) \\
1(10.0)\end{array}$ & $\begin{array}{l}3(13.6) \\
4(40.0)\end{array}$ & $\begin{array}{l}5(22.7) \\
5(50.0)\end{array}$ & $\begin{array}{c}10(45.5) \\
0(0)\end{array}$ \\
\hline $\begin{array}{l}\operatorname{IV}(+) \\
\operatorname{IV}(-)\end{array}$ & $\begin{array}{r}18(69.2) \\
4(66.7)\end{array}$ & $\begin{array}{l}8(30.8) \\
2(33.3)\end{array}$ & $\begin{array}{l}5(19.2) \\
0(0)\end{array}$ & $\begin{array}{l}1(3.8) \\
2(33.3)\end{array}$ & $\begin{array}{l}8(30.8) \\
1(16.7)\end{array}$ & $\begin{array}{r}12(46.2) \\
3(50.0)\end{array}$ \\
\hline
\end{tabular}

Numbers in parentheses show percentages

U, Upper-third; M, middle-third; L, lower-third; W, whole 
Table 6. Details of groups, with low and high IAP levels $(n=25$, total $)$

\begin{tabular}{lccc}
\hline & $\begin{array}{c}\text { Number of patients according to } \\
\text { stage of lymph node metastasis }\end{array}$ & Tumor size (mm) & Age (years) \\
\hline IAP $<450 \mu \mathrm{g} / \mathrm{ml}$ & $\mathrm{n} 0: 0$ & $116.6 \pm 55.4$ & $53.9 \pm 8.40$ \\
& $\mathrm{n} 1: 0$ & & \\
$\mathrm{n} 2: 8$ & & \\
$\mathrm{n} 3: 2$ & $107.5 \pm 45.8$ & $57.9 \pm 11.6$ \\
$\mathrm{IAP} \geqq 450 \mu \mathrm{g} / \mathrm{ml}$ & $\mathrm{n} 0: 4$ & & \\
& $\mathrm{n} 1: 4$ & & \\
$\mathrm{n} 2: 7$ & & \\
$\mathrm{n} 3: 0$ & & \\
\end{tabular}

IAP, Immunosuppressive acidic protein

Table 7. Details of PS and LUAE groups in $P$ - patients

\begin{tabular}{|c|c|c|c|}
\hline & $\begin{array}{l}\text { Number of patients according to } \\
\text { stage of lymph node metastasis }\end{array}$ & Tumor size (mm) & Age (years) \\
\hline PS group & $\begin{array}{l}\mathrm{n} 0: 7 \\
\mathrm{n} 1: 13 \\
\mathrm{n} 2: 15 \\
\mathrm{n} 3: 6\end{array}$ & $116.6 \pm 56.1$ & $54.1 \pm 10.6$ \\
\hline LUAE group & $\begin{array}{l}\mathrm{n} 0: 4 \\
\mathrm{n} 1: 6 \\
\mathrm{n} 2: 14 \\
\mathrm{n} 3: 2\end{array}$ & $134.0 \pm 33.6$ & $57.0 \pm 11.5$ \\
\hline
\end{tabular}

PS, Total gastrectomy combined with resection of the pancreatic body, tail, and spleen; LUAE, left upper abdominal evisceration

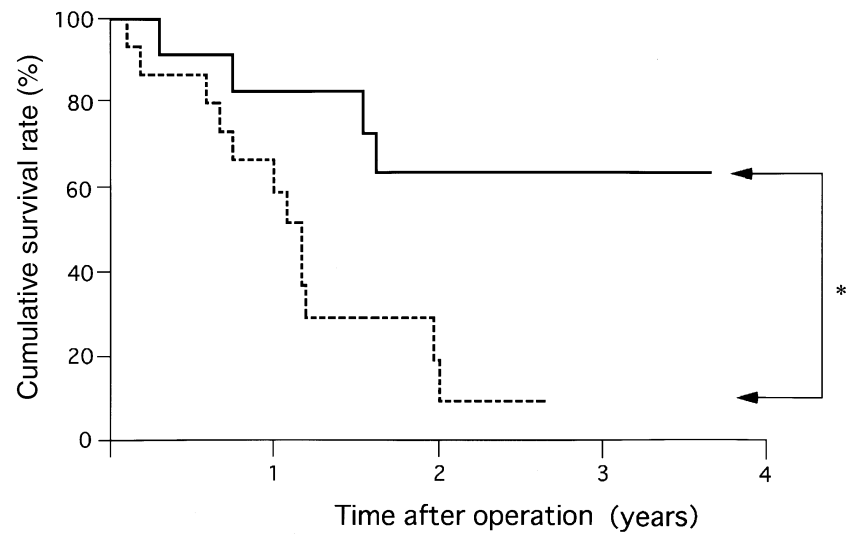

Fig. 3. Survival of patients who underwent gastrectomy plus IP therapy, stratified according to high and low levels of immunosuppressive acidic protein (IAP). Solid line indicates low-level IAP group (IAP $<450 \mu \mathrm{g} / \mathrm{ml}$ ); dashed line indicates high-level IAP group (IAP $\geqq 450 \mu \mathrm{g} / \mathrm{ml}$ ). $* P<0.05$

3 or type 4 tumors (Japanese classification [4]), with depth of invasion to the serosal surface, and without liver metastasis or lymph node metastasis around the abdominal aorta.

The most appropriate surgical approach (i.e., the extent of resection), for patients with advanced gastric cancer has yet to be clearly defined. Ooyama et al. [7] reported that LUAE had benefit, in terms of survival, if the (advanced) gastric cancer was located in the middle or upper portion of the stomach. Furukawa et al. [1] reported that the prognosis for patients with stage III or IV Borrmann type 4 gastric cancer was improved by LUAE, and that, compared with findings for standard total gastrectomy and pancreatosplenectomy, the incidence of peritoneal recurrence was lower. They speculated that the improvement in survival was mainly owing to the en-bloc removal of foci of macroscopically invisible peritoneal metastasis in the greater omentum.

Borrmann type 4 gastric cancers, in particular, tend to involve the greater omentum, either through direct invasion or through exfoliated cancer cells. The omentum, through what is termed "milky spots," has the ability to capture foreign bodies, bacteria, and cancer cells $[8,9]$. These milky spots are thought to allow cancer cells liberated in the abdominal cavity to enter the subperitoneal lymphatic space [10]. Yonemura et al. $[11,12]$ have suggested that the proliferation of exfoliated cancer cells in this subperitoneal lymphatic space may lead to peritoneal dissemination. Thus, it is likely that these spots also offer an alternative route for the distant metastasis of cancer cells. Some reports have indicated that extensive surgery such as LUAE did not 

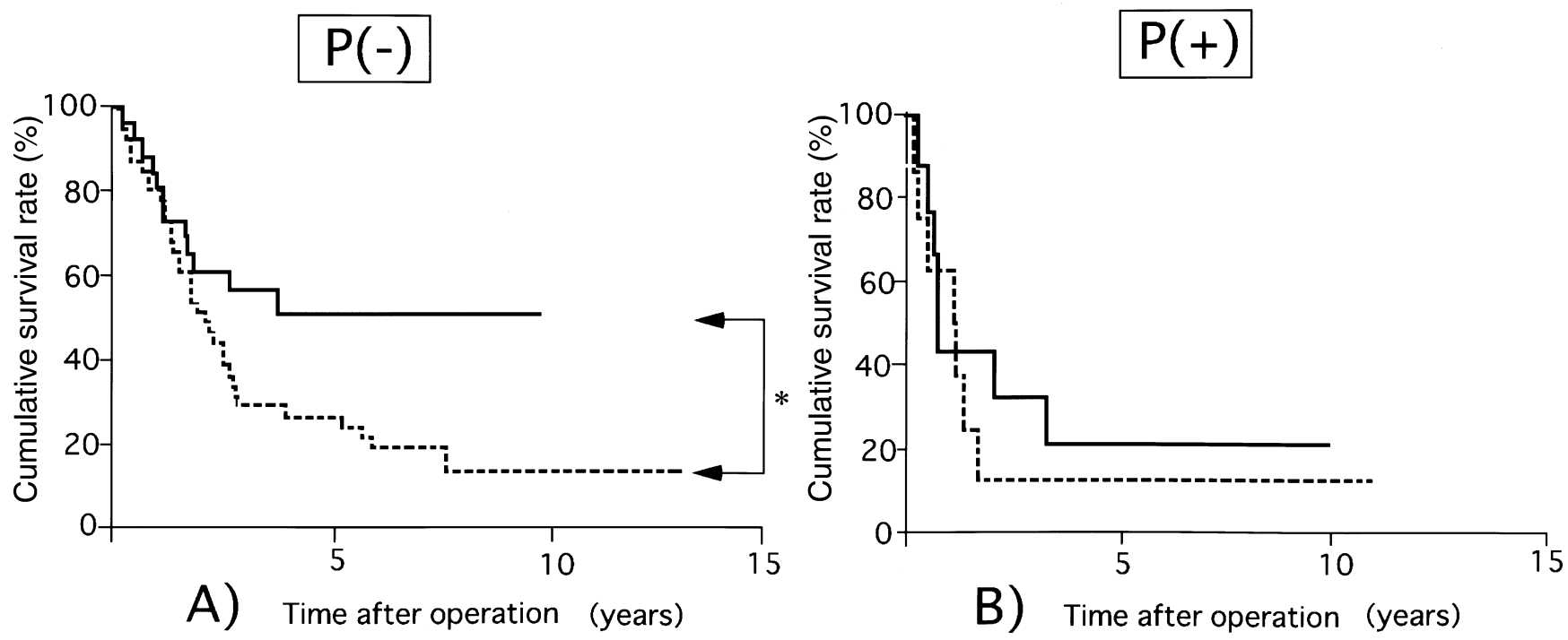

Fig. 4A,B. Survival of patients who underwent left upper abdominal evisceration (LUAE; solid line) versus survival of those who underwent total gastrectomy combined with resection of the pancreatic body, tail, and spleen (PS; dashed line). A P- patients who underwent LUAE versus those with PS; B P+ patients who underwent LUAE versus those with PS. * $P<0.05$

Table 8. Details of four patients with peritoneal dissemination who survived for more than 5 years

\begin{tabular}{|c|c|c|c|c|c|c|c|}
\hline $\begin{array}{l}\text { Age } \\
\text { (years) }\end{array}$ & Sex & $\begin{array}{l}\text { Tumor } \\
\text { location }\end{array}$ & $\begin{array}{l}\text { Macroscopic } \\
\text { type }^{\mathrm{a}}\end{array}$ & $\begin{array}{l}\text { Histological } \\
\text { findings }\end{array}$ & $\begin{array}{l}\text { Operative } \\
\text { procedure }\end{array}$ & Chemotherapy & $\begin{array}{l}\text { Survival } \\
\text { duration }\end{array}$ \\
\hline 37 & Male & MUL & Type 4 & $\begin{array}{l}\text { H0 P1 n1 se } \\
\text { por2 }\end{array}$ & $\begin{array}{l}\text { Total } \\
\text { gastrectomy } \\
+ \text { P S }\end{array}$ & $\operatorname{IP}(+), \operatorname{IV}(+)$ & $\begin{array}{l}10 \text { Years, } 10 \text { months; } \\
\text { not traceable thereafter }\end{array}$ \\
\hline 25 & Female & MUL & Type 4 & $\begin{array}{l}\mathrm{H} 0 \mathrm{P} 0 \mathrm{cy}(+) \mathrm{n} 2 \mathrm{se} \\
\text { por2 }\end{array}$ & LUAE & $\operatorname{IP}(+), \operatorname{IV}(+)$ & $\begin{array}{l}11 \text { Years, } 10 \text { months; } \\
\text { alive }\end{array}$ \\
\hline 42 & Female & MUL & Type 4 & $\begin{array}{l}\mathrm{H} 0 \mathrm{P} 3 \mathrm{cy}(+) \mathrm{n} 2 \mathrm{se} \\
\text { por2 }\end{array}$ & $\begin{array}{l}\text { Total } \\
\text { gastrectomy }\end{array}$ & $\operatorname{IP}(+), \operatorname{IV}(+)$ & $\begin{array}{l}6 \text { Years, } 2 \text { months; } \\
\text { alive }\end{array}$ \\
\hline 65 & Male & UMEL & Type 4 & $\begin{array}{l}\mathrm{H} 0 \mathrm{P} 1 \mathrm{n} 2 \mathrm{se} \\
\text { por2 }\end{array}$ & LUAE & $\operatorname{IP}(+) ; \operatorname{IV}(-)$ & $\begin{array}{l}5 \text { Years, } 3 \text { months; } \\
\text { not traceable thereafter }\end{array}$ \\
\hline
\end{tabular}

MUL, Tumor located in the middle third extends to the upper and lower third; UMEL, tumor located in the upper third extends to the middle third, esophagus, and lower third

${ }^{a}$ Classified according to reference [4]

always improve survival in patients with advanced gastric cancer [11]. The reason for this lack of improvement may be, in part, the disease situation in which macroscopically invisible cancer cells were already spread into the peritoneal cavity at the time of surgery, and in which the so-called milky spots were widely distributed in the abdominal cavity. For this reason, it was suggested that IP chemotherapy or hyperthermia, in addition to the extensive surgery, might have a role in treating patients with $\mathrm{T} 3$ or T4 tumors. Yonemura et al. [13] reported that continuous hyperthermic peritoneal perfusion (CHPP) with a solution that contained MMC and cisplatin had been introduced as a prophylactic treatment for peritoneal recurrence after curative resection of advanced gastric cancer, and a survival advantage was achieved for patients with pathologically confirmed serosal invasion-positive tumors (i.e., stage IV).

In our study also, LUAE compared with PS, failed to improve the survival of patients with peritoneal dissemination. It has been suggested that, for patients with peritoneal dissemination, there may be a role for moderate lymphadenectomy combined with IP chemotherapy during surgery and IV chemotherapy administered postoperatively [14]. This idea was substantiated in our study, in which $\mathrm{P}+$ patients had improved survival with combination IP and IV therapy. Specifically, MMC$\mathrm{CH}$ seems to be well suited for intraperitoneal administration. MMC-CH administered into the peritoneal cavity seems to adhere rapidly to the omentum and subphrenic/pelvic peritoneum, and to be absorbed into the lymphatic system $[4,15]$. In the present study, however, 
there was no survival advantage with the administration of MMC-CH compared with survival with MMC alone.

Bedikian et al. [16] reported that the strongest prognostic indicators of survival from the time of diagnosis of surgically noncurable disease were: status of the primary tumor, liver metastasis, serum bilirubin level, ascites, extent of tumor burden, two or more cycles of 5FU treatment, and weight loss. But they concluded that the effect of 5-FU on survival duration was, at best, minimal. Our analysis excluded the status of secondary tumor, liver metastasis, and clinically evident ascites; as for tumor burden, there were no significant differences among any of the groups. We could not suggest any such evident prognostic factors. However, our analysis suggests that aggressive combination therapy should be strongly considered for younger patients with peritoneal dissemination. This may especially be true for patients aged less than 60 years (who may have unperturbed immune systems [defined by low IAP levels], as shown in Fig. 3), or those with macroscopic type 4 cancers. A few such patients in our institution have been saved by this approach (Table 8). Moertel [17] described the natural history of incurable gastric cancer without any treatment, and reported that long-term survival in the face of incurable gastric cancer was quite rare, but that, nevertheless, it did occur, with $10 \%$ of patients being alive after 1 year, $2 \%$ alive after 5 years, and $1 \%$ alive after 10 years. However, at our institution, none of the patients without any treatment has survived for more than 2 years. Even if long-term survivors are very few, we should carry out appropriate treatment for patients who will be able to receive a benefit from such therapy.

In conclusion, our analysis indicates that LUAE may have a role in advanced gastric cancer, specifically in patients without peritoneal dissemination. In this group of patients in our study who underwent LUAE, the 5year survival was about $50 \%$, much higher than that in those without peritoneal dissemination who underwent PS.

\section{References}

1. Furukawa H, Hiratsuka M, Iwanaga T. A rational technique for surgical operation on Borrmann type 4 gastric carcinoma: left upper abdominal evisceration plus Appleby's method. Br J Surg 1988;75:116-9.

2. Kajitani T, Takagi K, Oohashi I. Radical gastrectomy (left side dissection) (in Japanese). Geka Shinryo (Surg Diagn Treat) 1982; 23:412-7.

3. Oohashi I, Takagi K, Kajitani T. Left upper abdominal evisceration for advanced gastrc carcinoma: indication and operative procedures (in Japanese). Gastroenterol Surg 1984;7:1535-42.

4. Japanese Research Society for Gastric Cancer. Japanese classification of gastric carcinoma (first English edition). Tokyo: Kanehara; 1995.

5. Hagiwara A. Mitomycin C adsorbed to activated carbon particles as a new drug dosage form for cancer chemotherapy(in Japanese). Akita J Med 1983;10:187-229.

6. Sakamoto J, Teramukai S, Koike A, Saji S, Ohashi Y, Nakazato $\mathrm{H}$. Prognostic value of preoperative immunosuppressive acidic protein in patients with gastric carcinoma. Findings from three independent clinical trials. Tumor Marker Committee for the Study Group of Immunochemotherapy with PSK for Gastric Cancer. Cancer 1996;77:2206-12.

7. Ooyama S, Nakajima F, Oota K, Ishihara S, Wakabayashi K, Nishi M. Left upper abdominal evisceration for advanced gastric cancer (in Japanese). Jpn J Cancer Chem 1994;21:1781-6.

8. Shimotsuma M, Kawata M, Hagiwara A, Takahashi T. Milky spots in human greater omentum. Acta Anat 1989;136:211-6.

9. Walker FC. The protective function of the greater omentum. Ann R Coll Surg Engl 1963;33:282-306.

10. Lawrence RJ, Loizidou M, Cooper AJ, Alexander P, Taylor I. Importance of the omentum in the development of intra-abdominal metastasis. Br J Surg 1991;78:117-9.

11. Yonemura Y, Kawamura T, Nojima N, Bandou E, Taniguchi K, Fujita $\mathrm{H}$, et al. Postoperative results of left upper abdominal evisceration for advanced gastric cancer. Hepatogastroenterology 2000;47:571-4.

12. Yonemura Y, Endou Y, Yamaguchi T, Fujimura T, et al. Mechanism of the formation of the peritoneal dissemination in gastric cancer. Int J Oncol 1996;8:795-802.

13. Yonemura Y, Ninomiya I, Kaji M, Sugiyama K, Fujimura K, Sawa T, et al. Prophylaxis with intraoperative chemohyperthemia against peritoneal recurrence of serosal invasion-positive gastric cancer. World J Surg 1995;19:450-4.

14. Konishi T. Treatment of scirrhous carcinoma of the stomach. Asian Med J 1996;39:291-9.

15. Hagiwara A, Takahashi T, Sawai S, Taniguchi H, Shimotsuma M, Okano S, et al. Milky spots as the implantation site for malignant cells in peritoneal dissemination in mice. Cancer Res 1993;53:68792.

16. Bedikian AY, Chen TT, Khankhanian N, Heibrun LK, McBride CM, McMurtrey MJ, Bodey GP. The natural history of gastric cancer and prognostic factors influencing survival. J Clin Oncol 1984;2:305-10.

17. Moertel CG. The natural history of advanced gastric cancer. Surg Gynecol Obstet 1968;1071-4. 